\title{
Monocyte Transmigration Induced by Modification of Low Density Lipoprotein in Cocultures of Human Aortic Wall Cells Is due to Induction of Monocyte Chemotactic Protein 1 Synthesis and Is Abolished by High Density Lipoprotein
}

\author{
Mahamad Navab, ${ }^{*}$ Susan S. Imes, ${ }^{\ddagger}$ Susan Y. Hama, ${ }^{*}$ Gregory P. Hough, ${ }^{*}$ Lori A. Ross, ${ }^{*}$ Richard W. Bork, \\ Anthony J. Valente," Judith A. Berliner," Davis C. Drinkwater,' Hillel Laks,' and Alan M. Fogelman* \\ Divisions of *Cardiology, and ${ }^{\ddagger}$ Hematology-Oncology, Department of Medicine, "Department of Pathology, and Division of \\ Cardiothoracic Surgery, 'Department of Surgery, School of Medicine, University of California Los Angeles, Los Angeles, \\ California 90024-167917; and ${ }^{\$}$ Department of Pathology, University of Texas, San Antonio, Texas 78284
}

\begin{abstract}
Incubation of cocultures of human aortic endothelial (HAEC) and smooth muscle cells (HASMC) with LDL in the presence of $5-10 \%$ human serum resulted in a 7.2-fold induction of mRNA for monocyte chemotactic protein 1 (MCP-1), a 2.5fold increase in the levels of MCP-1 protein in the coculture supernatants, and a 7.1-fold increase in the transmigration of monocytes into the subendothelial space of the cocultures. Monocyte migration was inhibited by $91 \%$ by antibody to MCP-1. Media collected from the cocultures that had been incubated with LDL induced target endothelial cells (EC) to bind monocyte but not neutrophil-like cells. Media collected from cocultures that had been incubated with LDL-induced monocyte migration into the subendothelial space of other cocultures that had not been exposed to $L D L$. In contrast, media from separate cultures of EC or smooth muscle cells (SMC) containing equal number of EC or SMC compared to coculture and incubated with the same LDL did not induce monocyte migration when incubated with the target cocultures. High density lipoprotein HDL, when presented to cocultures together with LDL, reduced the increased monocyte transmigration by 91\%. Virtually all of the HDL-mediated inhibition was accounted for by the $\mathrm{HDL}_{2}$ subfraction. $\mathrm{HDL}_{3}$ was essentially without effect. Apolipoprotein AI was also ineffective in preventing monocyte transmigration while phosphatidylcholine liposomes were as effective as $\mathrm{HDL}_{2}$ suggesting that lipid components of $\mathrm{HDL}_{2}$ may have been responsible for its action. Preincubating LDL with $\beta$-carotene or with $\alpha$-tocopherol did not reduce monocyte migration. However, pretreatment of LDL with probucol or pretreatment of the cocultures with probucol, $\beta$-carotene, or $\alpha$-tocopherol before the addition of LDL prevented the LDL-induced monocyte transmigration. Addition of HDL or probucol to LDL after the exposure to cocultures did not prevent the modified LDL from inducing monocyte transmigration in fresh cocultures. We conclude that cocultures of human aortic cells can modify LDL even in the presence of
\end{abstract}

Address correspondence to Dr. Mahamad Navab, Division of Cardiology, Room 47-123, Center for the Health Sciences, University of California, Los Angeles School of Medicine, Los Angeles, CA 90024167917. 1991.

Received for publication 8 May 1991 and in revised form 5 August

J. Clin. Invest.

(C) The American Society for Clinical Investigation, Inc. 0021-9738/91/12/2039/08 \$2.00

Volume 88, December 1991, 2039-2046 serum, resulting in the induction of MCP-1, and that HDL and antioxidants prevent the LDL induced monocyte transmigration. (J. Clin. Invest. 1991. 88:2039-2046.) Key words: endothelial $\bullet$ smooth muscle $\bullet$ vitamin $\mathbf{E} \cdot$ beta-carotene $\bullet$ probucol

\section{Introduction}

Accumulating evidence suggests that oxidized lipoproteins may play a critical role in the development of atherosclerosis. These lipoproteins have been observed in atherosclerotic plaques in human $(1,2)$ and in experimental animals (3-5). Additionally, the development of lesions in cholesterol-fed or Watanabe rabbits can be diminished by treatment with antioxidants such as probucol or butylated hydroxytoluene (6-8). LDL has been demonstrated to undergo modification by endothelial cells $(E C)^{1}(9,10)$, smooth muscle cells $(\operatorname{SMC})(9,11)$, and monocyte-macrophages (12) in culture in the absence of serum. In previous studies the inclusion of even small amounts of serum in the incubation media prevented the modification of LDL (13). Although the mechanism of modification of LDL in the vessel wall is not well understood, it must occur in the presence of plasma components with antioxidant properties such as $\alpha$-tocopherol, ceruloplasmin, or transferrin. We have used a coculture of human aortic EC and SMC (HAEC, HASMC) and studied the modification of native LDL in the presence of serum. We now report that incubation of LDL with artery wall cells results in a significant induction of monocyte chemotactic protein 1 (MCP-1) mRNA and protein, and in a marked increase in monocyte adhesion to and transmigration across the endothelial monolayer in the cocultures. HDL and antioxidants prevent these LDL-induced effects.

\section{Methods}

Materials. Tissue culture media, serum, supplements, and reagents for Northern analyses were obtained from sources reported $(14,15)$. Goat anti-rabbit immunoglobulin conjugated with alkaline phosphatase (\#A-7650) and egg phosphatidylcholine (\#P-1013) were purchased from Sigma Chemical Co., St. Louis, MO. Probucol was a gift of Dr. Richard Jackson, Merrell Dow Pharmaceuticals, Inc., Cincinnati, OH. Apoprotein AI was a gift of Dr. Henry J. Pownall, Baylor College of Medicine, Houston, TX.

Cocultures. HAEC, HASMC, and human peripheral blood monocytes were isolated as described (16). A 24-well unit was developed for

1. Abbreviations used in this paper: EC, endothelial cells; HAEC, human aortic EC; HASMC, human aortic smooth muscle cells; MCP-1, monocyte chemotactic protein 1; MM-LDL, minimally modified LDL; PC, phosphatidylcholine; SMC, smooth muscle cells. 
the study of monocyte transmigration. The unit illustrated diagrammatically in Fig. 1 was constructed from polycarbonate and is composed of a stainless steel base with 1-cm diameter openings, a polycarbonate sheet on top of the metal base that served as support for growing the cells and forming the cocultures, a nontoxic silicone gasket, and an upper template constructed from polycarbonate (Lexan; General Electric Plastics, Inc., Mt. Vernon, IN) that formed 24 wells containing the cocultures. The polycarbonate membrane was treated with $0.1 \%$ gelatin during sterilization in an autoclave, HASMC were seeded on the membrane in the unit at a confluent density of $1.5 \times 10^{5} \mathrm{cells} / \mathrm{cm}^{2}$ and cultured for $2 \mathrm{~d}$ at which time they covered the entire surface of the membrane and had produced a substantial amount of extracellular matrix. HAEC were subsequently seeded on top of the matrix HASMC at $2.5 \times 10^{5} \mathrm{cells} / \mathrm{cm}^{2}$ and allowed to grow forming a complete monolayer of confluent EC in $24 \mathrm{~h}(14,15)$. In all experiments, HAEC, and autologous HASMC (from the same donor) were used at passage levels of 5-10. The growth medium contained $10 \%$ heat inactivated pooled human serum and $10 \%$ fetal bovine serum in Iscove's modified Eagle's medium (IDME) or in medium 199. In some experiments cocultures were formed on filters attached onto inserts (Costar Corp., Cambridge, MA) or on discs made from polycarbonate membranes, in 24-well cell culture plates. Identical results were obtained with cocultures formed in the different systems used. Blood monocytes were obtained from individuals from a large pool of healthy donors by a modification of the Recalde procedure (16) and cryopreserved as previously described (15).

A

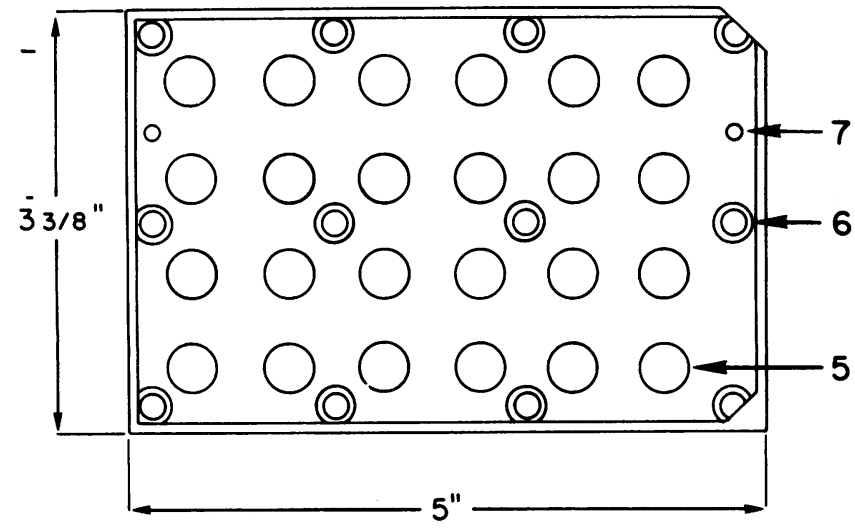

B

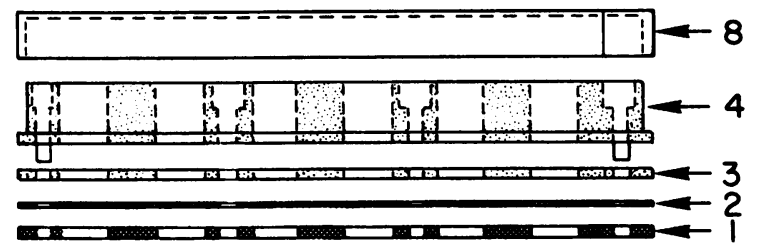

Figure 1. Schematic diagram of the multiwell unit for monocyte transmigration assay. The unit was constructed from: a stainless steel base (1) with $1-\mathrm{cm}$ diameter openings allowing microscopic examination of the cells; a polycarbonate membrane, 0.006 inch in thickness (2); a nontoxic silicone gasket 0.01 inch in thickness (3); and a template made from polycarbonate (4) with $1-\mathrm{cm}$ diameter holes (5) that formed 24 wells over the membrane. The unit is aligned using two dowels (6) and tightened with cap screws (7) and is covered with a 24-well cell culture plate lid $(8)$. $(A)$ Top view; $(B)$ side view crosssection.
The human monocytes isolated by the modified Recalde procedure and cryopreserved have been demonstrated to be comparable with monocytes isolated by conventional procedures in terms of cell viability, protein content, purity, and monocyte chemotaxis (15).

Northern analyses. A 738-bp MCP-1 insert was removed from an MCP-1/pUC18 construct by digestion with EcoRI and BamHI according to the instructions provided by American Type Culture Collection, Rockville, MD. The MCP-1 cDNA insert was then purified by electrophoresis through agarose gel and was nick translated to a sp act of 8 $\times 10^{8} \mathrm{cpm} / \mu \mathrm{g}$ cDNA insert using a $\left.{ }^{32} \mathrm{P}\right]$ dCTP nick translation kit (Pharmacia LKB Biotechnology Inc., Piscataway, NJ). For Northern blot analyses, the media were removed, cell layers were washed with PBS, pH 7.4, and total cellular RNA was isolated by lysis of cell layers in guanidinium isothiocyanate, phenol-chloroform extraction, and precipitation (17). $10 \mu \mathrm{g}$ of each RNA preparation from cocultures or components was denatured and subjected to electrophoresis on a $1.2 \%$ formaldehyde agarose gel. This was followed by blotting onto nylon filters and UV crosslinking (15). The blots were prehybridized for $1 \mathrm{~h}$ at $65^{\circ} \mathrm{C}$. The buffer was then discarded and the hybridization to the cDNA probe for MCP-1 was performed in the same buffer for $16 \mathrm{~h}$ at $55^{\circ} \mathrm{C}(15)$. The probe was previously labeled to a sp act of $\sim 10^{\circ} \mathrm{cpm} /$ $\mu \mathrm{g}(18)$ and $2 \times 10^{6} \mathrm{cpm} / \mathrm{ml}$ was used for each blot. The blots were then washed once for $30 \mathrm{~s}$ with $100 \mathrm{ml}$ of $2 \times \mathrm{SSC}$, twice with $500 \mathrm{ml}$ of $1 \times$ SSC for 30 min each at room temperature, and twice with $0.5 \times$ SSC for $30 \mathrm{~min}$ each at $55^{\circ} \mathrm{C}$ and were autoradiographed. The autoradiographs were scanned by laser densitometry, signals were quantitated, and were normalized for $\alpha$-tubulin values.

Lipoproteins. LDL $(\mathrm{d}=1.019-1.063)$ and total HDL $(\mathrm{d}=1.065-$ 1.21), $\mathrm{HDL}_{2}(\mathrm{~d}=1.065-1.125)$, and $\mathrm{HDL}_{3}(\mathrm{~d}=1.125-1.21)$ were isolated from the plasma of normal blood donors by density gradient ultracentrifugation as described (19) and were used within 2-4 wk of isolation. The concentration of lipoproteins is expressed in terms of protein content throughout this report.

Phosphatidylcholine liposomes. Egg phosphatidylcholine (PC) was dissolved in chloroform, the solvent was completely evaporated under a stream of nitrogen, PBS pH 7.4, was added and the dispersion was exposed to $4 \times 10$-s pulses of sonication under argon and at $4^{\circ} \mathrm{C}$.

ELISA for $M C P-1$. Using the antibody prepared in a rabbit, against purified baboon aortic SMC (20) later shown to be the same as the monocyte chemotactic protein 1 (21), an ELISA was developed for measuring the concentration of MCP-1 in the culture supernatants. Briefly, Immulon I plates (Dynatech Laboratories, Inc., Alexandria, VA) were coated with anti-MCP-1 diluted to $1: 100,000$ and kept at $4^{\circ} \mathrm{C}$ for $16 \mathrm{~h}$. Plates were then washed five times with PBS-Tween. Test samples or pure MCP-1 standard solutions were diluted in PBS-Tween and were incubated for $45 \mathrm{~min}$ at $37^{\circ} \mathrm{C}$ and were kept at $4^{\circ} \mathrm{C}$ for $16 \mathrm{~h}$. Plates were then washed five times with PBS-Tween and were incubated with a $1: 2,000$ dilution of anti-MCP-1 antibody at $37^{\circ} \mathrm{C}$ for 45 min followed by five times washing with PBS-Tween and incubation with $100 \mu \mathrm{l} /$ well of $1: 2,000$ dilution of a goat anti-rabbit IgG conjugated with alkaline phosphatase. After $45 \mathrm{~min}$ of incubation at $37^{\circ} \mathrm{C}$ plates were washed and $200 \mu \mathrm{l}$ of $1 \mu \mathrm{g} / \mathrm{ml} p$-nitrophenylphosphate was added. Plates were kept in the dark at room temperature and optical density at $405 \mathrm{~nm}$ was determined in an ELISA reader (Molecular Devices Corp., Menlo Park, CA). The concentration of MCP-1 in culture supernatants was determined using the linear portion of the standard curve constructed using pure MCP-1.

Monocyte transmigration. Monocytes were labeled with the fluorescent probe $1,1^{\prime}$-dioctadecyl-3,3,3',3'-tetramethyl-indo-carbocyanine perchlorate (Dil) at $4^{\circ} \mathrm{C}$ for $10 \mathrm{~min}(22)$. The cocultures were treated with native LDL $(100 \mu \mathrm{g} / \mathrm{ml}), \mathrm{LDL}+$ antibody to MCP-1, or LDL + irrelevant antibody. The culture supernatants were subsequently transferred to untreated cocultures and were incubated for a second 24 h. The cocultures were subsequently washed with culture medium at $37^{\circ} \mathrm{C}$ and Dil-labeled monocytes were placed on cocultures in the multiwell unit at $2.5 \times 10^{5}$ cells $/ 0.5 \mathrm{ml} \mathrm{per} \mathrm{cm}^{2}$ and were incubated for 60 min at $37^{\circ} \mathrm{C}$. The IDME medium used contained $0.5 \%$ heat inactivated pooled human serum. The medium containing nonadherent leukocytes was then removed, cell layers were washed at $37^{\circ} \mathrm{C}$ to remove 
the loosely adherent monocytes on top of the EC. The cocultures on the polycarbonate membranes were fixed with $10 \%$ neutral buffered formalin at room temperature for $24 \mathrm{~h}$ and were mounted on glass slides. The number of monocytes in the subendothelial space (beneath the ECs) in a minimum of nine fields were determined under 500 magnification and fluorescence microscopy.

Monocyte adhesion assay. Medium conditioned by cocultures for $24 \mathrm{~h}$ was transferred to confluent endothelial monolayers in 48-well tissue culture plates (23) and the plates were incubated for $4 \mathrm{~h}$ at $37^{\circ} \mathrm{C}$. The medium was then removed and the EC layers were washed three times with RPMI 1640 containing $1 \%$ (vol/vol) fetal bovine serum. Monocytes or THP-1 cells (from a monocyte-like cell line) were placed on EC at $1.2 \times 10^{5} \mathrm{cells} / \mathrm{cm}^{2}$, and the dishes were incubated for $30 \mathrm{~min}$ at $37^{\circ} \mathrm{C}$. The suspension was removed, the cell layers were vigorously washed three times to remove all but the firmly adherent monocytes or THP-1 cells on EC. To some wells the neutrophil-like, HL-60 cells (from a promyelocytic cell line) were added in place of THP-1. The number of adherent leukocytes was determined in 20 microscopic fields.

Other procedures. Measurement of cell protein content was done by the method of Lowry et al. (24) and determination of cell number was carried out by standard procedures (25). The level of thiobarbituric reactive substances was measured using a modification of the procedure described by Morel et al. (26) provided by Drs. Guy Chisolm and Paul DiCorleto of The Research Institute of The Cleveland Clinic Foundation, $\mathrm{OH}$. Fluorescence was determined with excitation at 360 $\mathrm{nm}$ and emission maximum at $430 \mathrm{~nm}$ with excitation and emission slits maintained at $5 \mathrm{~nm}$. Gel electrophoresis was carried out using $0.7 \%$ agarose gel at pH 8.6 in $0.05 \mathrm{M}$ barbital buffer. The assay for macrophage degradation of lipoproteins was conducted as previously reported (27).

\section{Results}

Conditioned medium containing LDL (at $500 \mu \mathrm{g} / \mathrm{ml}$ ) previously incubated with cocultures of human aortic wall cells containing $5 \%$ serum for $24 \mathrm{~h}$ at $37^{\circ} \mathrm{C}$, induced a 2.8 -fold increase in the number of monocytes that adhered to target endothelial monolayers as compared to the coculture conditioned medium that did not contain the additional LDL (Fig. $2 A$; compare $E C / S M C+L D L$ and $E C / S M C, N O L D L)$. LDL incubated in the same tissue culture medium containing $5 \%$ serum in the absence of cells, did not induce monocyte adhesion to the EC monolayers (Fig. $2 A$, NO CELLS, $+L D L$ ). In contrast, adhesion of neutrophil-like cells to EC monolayers was not induced by LDL containing medium that was previously incubated with cocultures (Fig. $2 A, E C / S M C+L D L, P M N S$ ). In other studies cocultures of HAEC and HASMC were incubated in the presence of $5-10 \%$ human serum and some were supplemented with $100 \mu \mathrm{g} / \mathrm{ml}$ of LDL in the absence or presence of antibody. After $24 \mathrm{~h}$ the conditioned media were removed and incubated with untreated cocultures for an additional $24 \mathrm{~h}$. The media were removed and human monocytes were added to the cocultures and their transmigration into the subendothelial space of the cocultures was determined (Fig. $2 \mathrm{~B}$ ). Incubation of LDL with cocultures induced a 7.1-fold increase in monocyte migration into the subendothelial space. This effect was comparable to that induced by the potent chemoattractant FMLP. The presence of antibody to MCP-1 abolished the induced monocyte migration by $91 \%$ while an irrelevant immunoglobulin did not have a significant effect. As shown in Fig. 3 $A$, incubation of LDL at $500 \mu \mathrm{g} / \mathrm{ml}$ with cocultures of HAEC and HASMC for $24 \mathrm{~h}$ resulted in a marked induction of message for MCP-1 which was 7.2-fold greater than the sum of the values determined for EC and SMC cultured separately. Super-
$\boldsymbol{A}$

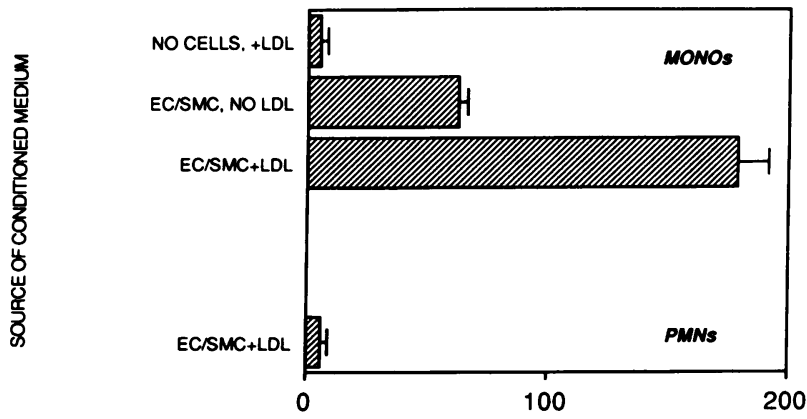

ADHERENT LEUKOCYTES / HPF

B

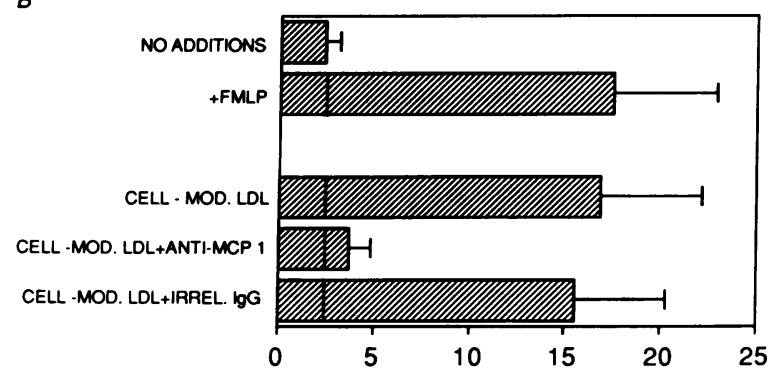

MONOCYTES / HPF

Figure 2. (A) Effect of coculture modified-LDL on monocyte adhesion to target EC. Cocultures of human aortic EC and SMC in the presence of $5 \%$ serum were incubated in the absence $(E C / S M C, N O$ $L D L)$ or presence $(E C / S M C,+L D L)$ of $L D L$ at $500 \mu \mathrm{g} / \mathrm{ml}$ for $24 \mathrm{~h}$. The conditioned medium was collected and was incubated with target EC monolayers for $4 \mathrm{~h}$. The monolayers were subsequently washed with culture medium and monocytes or neutrophil-like cells (PMNs) were added to EC layers and incubated for $30 \mathrm{~min}$. The monolayers were then vigorously washed to remove the loosely adherent cells and the adherent leukocytes were enumerated under 500 magnification. The values are mean \pm SD of number of adherent leukocytes in 20 fields in triplicate wells in two separate experiments. $(B)$ Monocyte transmigration into the subendothelial space. Cocultures of HAEC and HASMC on polycarbonate membranes were incubated with 100 $\mu \mathrm{g} / \mathrm{ml}$ of LDL in the presence of 5-10\% serum $(L D L)$. Some of the cocultures contained Fab fragments prepared from an antibody to MCP-1, (+ANTI MCP-I), or from an irrelevent antibody, (+IRREL. $I g G$ ). After $24 \mathrm{~h}$, the supernatants containing the cell modified LDL (CELL-MOD. $L D L)$ were transferred to fresh sets of cocultures CELL-MOD. LDL; CELL-MOD. LDL + ANTI MCP-1; CELLMOD. $L D L+I R R E L$. IgG and incubated for an additional $24 \mathrm{~h}$. The culture medium was then removed, the cell layers were washed at $37^{\circ} \mathrm{C}$, and fluorescently labeled human monocytes were added at 2.5 $\times 10^{5}$ cells $/ 0.5 \mathrm{ml}$ per $\mathrm{cm}^{2}$. Some of the cocultures without LDL received the reference chemoatractant f-met-leu-phe $1 \mathrm{~h}$ before the addition of monocytes $(+F M L P)$. After $60 \mathrm{~min}$ at $37^{\circ} \mathrm{C}$, the media were removed, the cocultures were washed at $37^{\circ} \mathrm{C}$, and the preparations were fixed with $10 \%$ neutral buffered formalin for $24 \mathrm{~h}$. The membranes or discs were mounted on glass slides and the subendothelial monocytes were enumerated under 500 magnification. The values are mean $\pm \mathrm{SD}$ of monocytes from 27 fields in triplicate cocultures. This figure is a representative of two separate experiments.

natants of additional cocultures which were previously incubated with medium containing LDL at $100 \mu \mathrm{g} / \mathrm{ml}$ for $36 \mathrm{~h}$ in the presence of serum, contained 2.5-fold higher levels of 


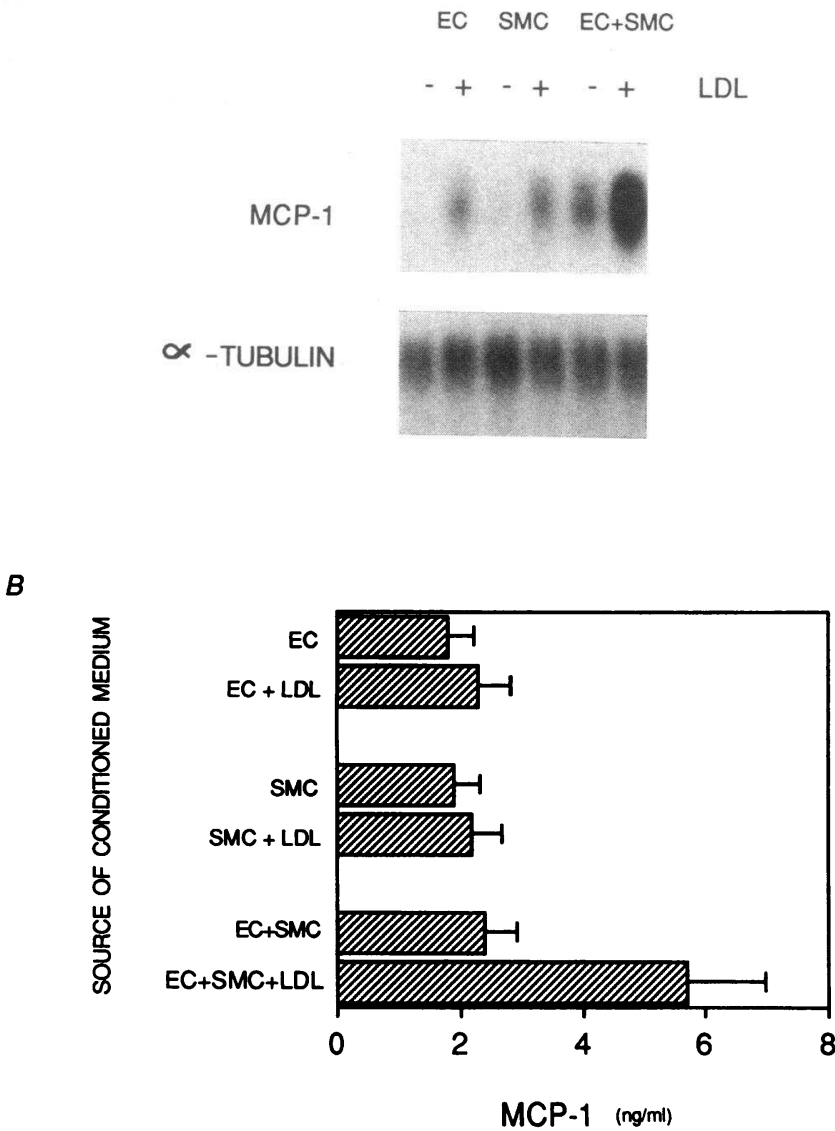

Figure 3. $(A)$ Induction of MCP-1 message. Cocultures of human aortic EC and SMC or their components were incubated with 500 $\mu \mathrm{g} / \mathrm{ml}$ of LDL in medium containing $5 \%$ serum for $36 \mathrm{~h}$. Total RNA was isolated and $10-\mu \mathrm{g}$ samples were subjected to Northern analysis and were probed for human MCP-1 and for $\alpha$-tubulin. (B) Levels of MCP- 1 in culture supernatants. Cocultures of HAEC and HASMC or their components were incubated in the presence of $5 \%$ human serum without additions $(E C, S M C, E C+S M C)$ or with $100 \mu \mathrm{g} / \mathrm{ml}$ of $\operatorname{LDL}(E C+L D L, S M C+L D L, E C+S M C+L D L)$. After $24 \mathrm{~h}$, the cultures were washed and incubated in serum-free medium for $24 \mathrm{~h}$. The culture supernatants were then analyzed in an ELISA for MCP-1. The data are the mean \pm SD from six determinations in two separate experiments.

MCP-1 than did the coculture with no LDL treatment (Fig. 3 $B)$. Supernatants of cocultures without added LDL contained levels of MCP-1 comparable to that from the individual cell types without added LDL (Fig. $3 B$ ). Incubation of LDL with EC or SMC alone did not increase the MCP-1 levels in the culture supernatants (Fig. $3 \mathrm{~B}$ ). Incubation of cocultures with the reference chemoattractant FMLP did not result in increased levels of MCP-1 (data not shown).

As shown in Fig. $4 \mathrm{~A}$, the presence of LDL in the coculture for $4 \mathrm{~h}$ was insufficient to induce monocyte migration (Fig. $4 \mathrm{~A}$ ) but after $48 \mathrm{~h}$ of incubation with LDL, a 5.8-fold increase in monocyte migration into the subendothelial space was observed. Inclusion of HDL by itself for $48 \mathrm{~h}$ had no effect on the number of monocytes in the subendothelial space (Fig. $4 \mathrm{~A}$ ) but the inclusion of HDL $(50 \mu \mathrm{g} / \mathrm{ml})$ with LDL $(100 \mu \mathrm{g} / \mathrm{ml})$ inhibited the induced increase in monocyte migration by $91 \%$. In additional experiments $\mathrm{HDL}$, at $50 \mu \mathrm{g} / \mathrm{ml}$, was previously oxidized by incubation with coculture for $24 \mathrm{~h}$ and subsequently was transferred to untreated cocultures and was tested for its ability to prevent $\mathrm{LDL}$, at $100 \mu \mathrm{g} / \mathrm{ml}$, from modification. Oxidized HDL was found to reduce the LDL-induced monocyte transmigration by 59 to $77 \%$, compared to $91 \%$ for native HDL (data not shown). The experiments in Fig. $4 \mathrm{~A}$ also demonstrated that LDL and HDL needed to be in contact with the

$A$

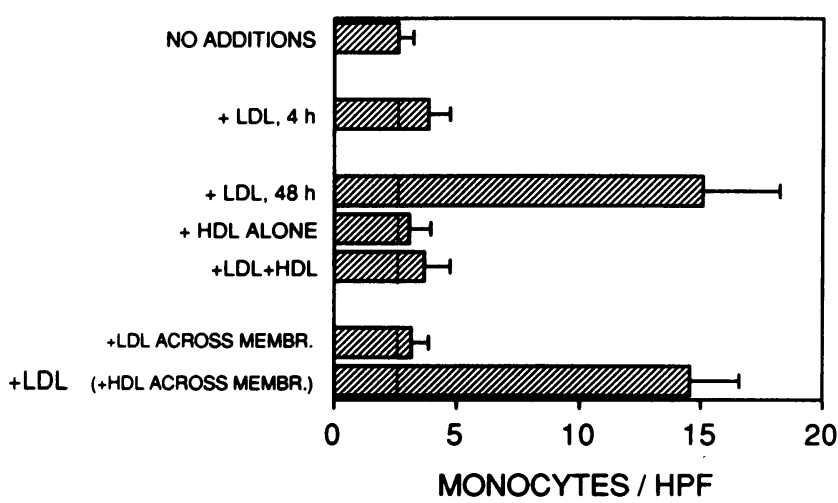

$B$

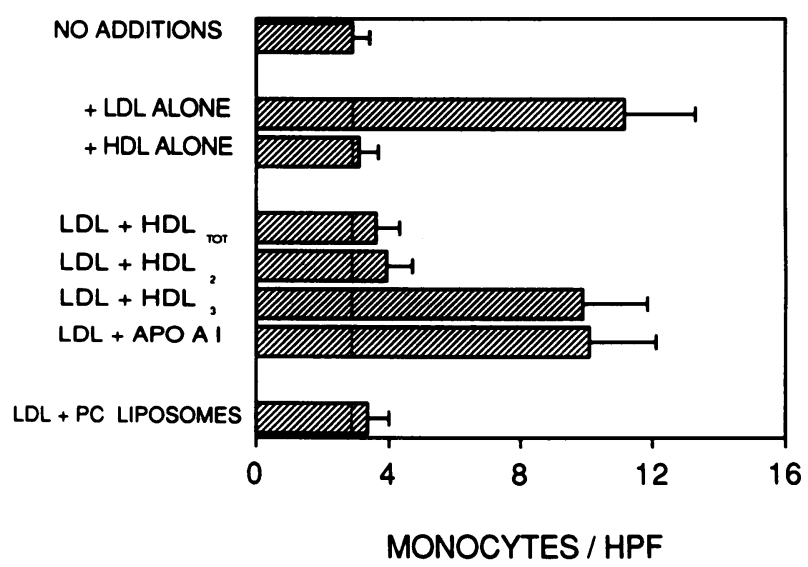

Figure 4. Effect of HDL on monocyte transmigration. (A) Cocultures of HAEC and HASMC were incubated with $100 \mu \mathrm{g} / \mathrm{ml}$ of LDL, $(+L D L)$. HDL was added at $50 \mu \mathrm{g} / \mathrm{ml}$ to some of these cocultures, $(+L D L+H D L)$. Other cocultures received only HDL and no LDL, $(+H D L A L O N E)$. Additional cocultures were incubated with LDL for only $4 \mathrm{~h}$ before the addition of monocytes, $(+L D L, 4 h)$. Other treatments consisted of incubation with LDL that was separated from the cells by a dialysis membrane with a molecular cut-off point of 12,000 , designated as $+L D L A C R O S S M E M B R$. or with HDL that was separated from cells and the medium containing LDL by a dialysis membrane designated as +LDL ( $+H D L A C R O S S M E M B R$.). Monocyte transmigration was tested as described for Fig. $2 B$. The values are mean $\pm \mathrm{SD}$ of number of monocytes in the subendothelial space of 12-48 cocultures in two to six separate experiments. $(B)$ Effect of HDL subfractions and phospholipid liposomes. Cocultures of EC and SMC were incubated with $100 \mu \mathrm{g} / \mathrm{ml}$ of LDL for $48 \mathrm{~h}$ ( $+L D L$ $A L O N E$ ). Some of the cocultures received $50 \mu \mathrm{g} / \mathrm{ml}$ of HDL ( $L D L$ $\left.+H D L_{\text {Tot. }}\right)$ or $33 \mu \mathrm{g} / \mathrm{ml}$ of $\mathrm{HDL}_{2}\left(L D L+H D L_{2}\right)$ or 17 or $33 \mu \mathrm{g} / \mathrm{ml}$ of $\mathrm{HDL}_{3}\left(L D L+H D L_{3}\right)$. Other cocultures received in addition to LDL, apolipoprotein AI, $50-500 \mu \mathrm{g} / \mathrm{ml}(L D L+A P O A I)$ or phosphatidylcholine liposomes at $28 \mu \mathrm{g} / \mathrm{ml}$ ( $L D L+P C$ LIPOSOMES). Monocyte transmigration assay was conducted as described for Fig. $2 \mathrm{~B}$. The values are mean \pm SD of number of subendothelial monocytes in 27 high power fields in triplicate cocultures in four separate experiments. 
cells to modulate these events. The inhibitory effect on monocyte migration observed using total HDL was basically mimicked by the $\mathrm{HDL}_{2}$ subfraction at $33 \mu \mathrm{g} / \mathrm{ml}$ (Fig. $4 \mathrm{~B}$ ). Inclusion of $\mathrm{HDL}_{3}$ at 17 or $33 \mu \mathrm{g} / \mathrm{ml}$ did not inhibit the stimulatory effect of the LDL in monocyte transmigration (Fig. $4 \mathrm{~B}$ ). Additionally, the incubation of apolipoprotein $\mathrm{AI}$ in a concentration range of $50-500 \mu \mathrm{g} / \mathrm{ml}$ along with $L D L$ did not effect the LDL induced increase in the number of monocytes in the subendothelial space of cocultures (Fig. $4 \mathrm{~B}$ ). Phosphatidylcholine liposomes at $28 \mu \mathrm{g} / \mathrm{ml}$ (a concentration comparable to that of the phospholipids in $50 \mu \mathrm{g} / \mathrm{ml}$ of HDL) were able to inhibit the LDL-induced increase in monocyte transmigration by $83, \%$ (Fig. 4 B). Incubation of PC liposomes alone (at 28-112 $\mu \mathrm{g} / \mathrm{ml}$ ) with cocultures for $48 \mathrm{~h}$ did not result in increased monocyte transmigration (data not shown).

Preincubation of the cocultures for $16 \mathrm{~h}$ with probucol, $\alpha$-tocopherol, or $\beta$-carotene at $5.0 \mu \mathrm{M}$ prevented the LDL-induced monocyte migration by $>82 \%$ (Fig. $5 \mathrm{~A}$ ). Preincubation of LDL with $\alpha$-tocopherol or $\beta$-carotene at 10-50 $\mu \mathrm{M}$ did not prevent the LDL modification and the subsequent monocyte migration while preincubation of LDL with probucol at 2-5 $\mu \mathrm{M}$ inhibited the monocyte migration by $89 \%$ (Fig. $5 \mathrm{~A}$ ).

In other experiments, native LDL at $250 \mu \mathrm{g} / \mathrm{ml}$ was incubated with cocultures for $24 \mathrm{~h}$ and LDL was reisolated from the resulting conditioned medium. This LDL was subsequently incubated (at $50 \mu \mathrm{g} \mathrm{LDL} / \mathrm{ml}$ ) with new cocultures in $5 \%$ human serum for $24 \mathrm{~h}$. There was a 3.9-fold increase in the number of monocytes that migrated to the subendothelial space of cocultures incubated with this cell-modified LDL (Fig. $5 \mathrm{~B}$ ). Coincubation of the reisolated LDL with HDL, or with probucol in cocultures did not prevent the LDL induced monocyte transmigration (Fig. $5 \mathrm{~B}$ ). Similar results were obtained when LDL was incubated with cocultures and the resulting conditioned medium, without reisolating its LDL, was transferred to, and incubated with fresh cocultures (Fig. $2 B, C E L L-M O D$. $L D L)$. Preincubation of LDL with EC or SMC in separate cultures did not produce a significant LDL induced increase in monocyte migration (Fig. $5 \mathrm{~B}$ ). Coincubation of PC liposomes with the cell-modified LDL did not change the number of monocytes in the subendothelial space of cocultures (data not shown). The presence of HDL, probucol, or PC liposomes did not affect monocyte transmigration itself since the inclusion of these compounds in cocultures containing the reference chemoattractant FMLP did not affect the number of monocytes in the subendothelial space (data not shown).

The reisolated modified LDL produced in the serum containing cocultures was examined for the changes associated with highly oxidized LDL (12). The LDL reisolated from the cocultures had a buoyant density similar to that of native LDL ( $d=1.019-1.063$ ), was not toxic to the HAEC, HASMC, or human monocytes and was not chemotactic for monocytes by itself (data not shown). Moreover the LDL reisolated from the cocultures had the same electrophoretic mobility on agarose gel, the same content of thiobarbituric reactive substances, the same fluorescence emission at $430 \mathrm{~nm}$ when excited at $360 \mathrm{~nm}$, and the same rate of uptake and degradation by human monocyte-macrophages as did native LDL (data not shown).

\section{Discussion}

Incubation of native LDL with serum containing cocultures of human aortic wall cells for $24-48 \mathrm{~h}$ resulted in a marked induction of monocyte binding to target EC and transmigration and localization in the subendothelial space of the cocultures (Fig. 2 ). The increase in monocyte migration was most likely due to the increased levels of MCP-1 since: it was completely blocked by a specific antibody to MCP-1 (Fig. $2 \mathrm{~B}$ ); it was preceded by a marked induction of mRNA for MCP-1 (Fig. $3 \mathrm{~A}$ ); and it was associated with increased levels of MCP-1 protein (Fig. $3 \mathrm{~B}$ ). Inclusion of HDL along with LDL inhibited the observed induction of monocyte transmigration as did the pretreatment of cocultures with antioxidants (Figs. 4 and 5). The effect of HDL

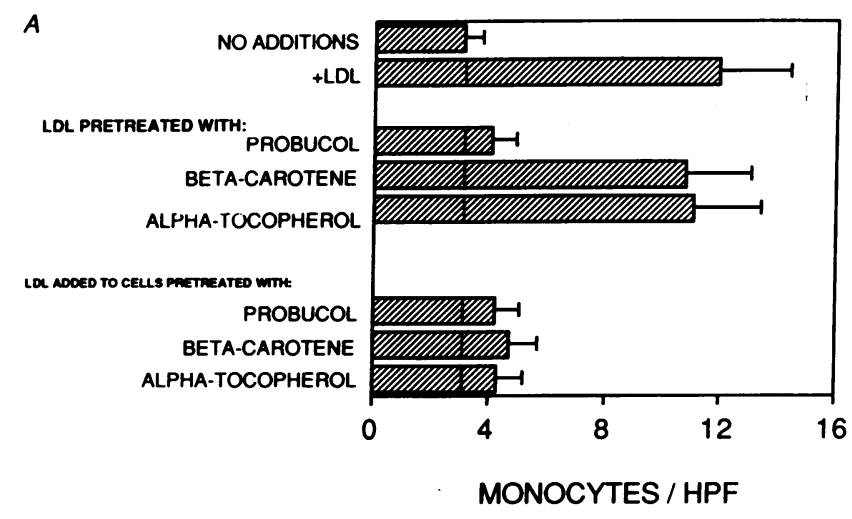

$B$

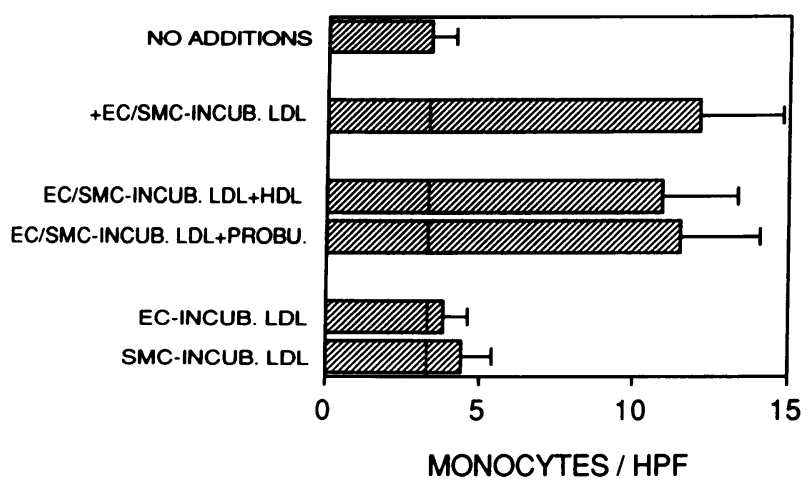

Figure 5. $(A)$ Pretreatment with antioxidants. Cocultures of HAEC and HASMC were incubated with $100 \mu \mathrm{g} / \mathrm{ml}$ of LDL, $(+L D L)$. For some cocultures the added LDL was previously incubated with probucol, $\beta$-carotene, or $\alpha$-tocopherol at 5-50 $\mu \mathrm{M}$ (LDL PRETREATED WITH PROBUCOL, $\beta$-CAROTENE, OR ALPHA-TOCOPHEROL) at $37^{\circ} \mathrm{C}$ for $16 \mathrm{~h}$. In other cocultures the cells were preincubated with probucol, $\beta$-carotene, or $\alpha$-tocopherol at 2-10 $\mu \mathrm{M}$ (LDL ADDED TO CELLS PRETREATED WITH PROBUCOL, $\beta$-CAROTENE, OR ALPHA-TOCOPHEROL) at $37^{\circ} \mathrm{C}$ for $16 \mathrm{~h}$. The cells were then washed twice for $1 \mathrm{~h}$ at $37^{\circ} \mathrm{C}$ and were incubated with $100 \mu \mathrm{g} / \mathrm{ml}$ of LDL for $48 \mathrm{~h}$. Monocyte transmigration assay was conducted as described for Fig. $2 \mathrm{~B}$. The values are mean \pm SD of number of subendothelial monocytes in $\mathbf{2 7}$ high power fields in three cocultures in three separate experiments. $(B)$ The effect of cell-modified LDL. After $24 \mathrm{~h}$ of incubation with cocultures or their components, LDL was reisolated from the conditioned medium by density gradient centrifugation and was exposed to fresh target cocultures for $24 \mathrm{~h}(+E C)$ $S M C-I N C U B . L D L)$ at a concentration of $50 \mu \mathrm{g} \mathrm{LDL} / \mathrm{ml}$. Other target cocultures received HDL (at $50 \mu \mathrm{g} / \mathrm{ml}$ ) or probucol (at $5 \mu \mathrm{M}$ ) in addition to the cell-modified LDL, designated as $+E C / S M C-I N C U B$. $L D L+H D L$, and $+E C / S M C-I N C U B . L D L+P R O B U$., respectively. Some cocultures received LDL that had previously been incubated with HAEC or HASMC in separate cultures referred to as $E C$ INCUB. $L D L$ and SMC-INCUB. $L D L$, respectively. Monocyte migration was evaluated as described for Fig. $2 B$. The values are mean \pm SD of number of monocytes in 27 fields in triplicate cocultures in each treatment in three separate experiments. 
and antioxidants appeared to be confined to the events that occurred during the initial steps of interaction of LDL and the artery wall cells, since HDL or antioxidants did not prevent the induction of monocyte transmigration brought about by LDL that had previously been incubated with, presumably modified by cocultures, and subsequently incubated with fresh sets of untreated cocultures (Fig. $5 \mathrm{~B}$ ). Incubation of LDL with HAEC alone or HASMC alone did not result in increased monocyte transmigration (Fig. $5 B$ ). Therefore, it appears likely that LDL is modified in the microenvironment formed by the extracellular matrix components produced by the interaction of HAEC and HASMC $(14,15,29)$. Serum, a potent suppressant of celldependent modification of LDL (12) is apparently excluded from this space. The coculture-modified LDL then induces MCP-1 production by EC and SMC which presumably results in the establishment of a chemotactic gradient across the endothelial monolayer in the coculture. Previous studies of the modification of $\operatorname{LDL}$ by $\operatorname{EC}(9,10)$, by $\operatorname{SMC}(9,11)$, and by macrophages (12) in culture all used serum-free medium and obtained highly modified LDL (13). In addition, the culture medium used in these studies (Ham's F10) contained eight times higher levels of iron (compared to medium 199 used in our study) which is known to catalyze the oxidation of LDL $(10,11)$. The mild degree of modification produced in the coculture system is presumably a result of the action of prooxidants in the microenvironment largely sequestered from the effect of antioxidants present in the serum in the coculture. We observed that the LDL and the artery wall cells had to be in a close contact to stimulate monocyte transmigration (Fig. $4 \mathrm{~A}$ ). Similarly, the protective effect of HDL was eliminated if HDL was separated from the cells and LDL by a filter that was impermeable to HDL (Fig. $4 A$ ). The mechanism of LDL modification in the artery wall is not known. The modification might result from the release of superoxide anions from the artery wall cells, the action of membrane bound enzymes on LDL, and/or the transfer of cellular lipid peroxides to LDL (13). The loss of antioxidants such as $\alpha$-tocopherol and the peroxidation of polyunsaturated fatty acids in the LDL lipids appears to be the initiation step in the modification of LDL (30). Morel and colleagues (9) and Steinbrecher et al. (10) have demonstrated that cellular modification of LDL was completely inhibited by $\alpha$-tocopherol or butylated hydroxytoluene. Copper or iron at sufficiently high concentrations (3-5 $\mu \mathrm{M})$ in the absence of serum are capable of producing oxidatively modified LDL (10). This has prompted the suggestion that the major contribution of the cells in LDL modification is to enhance the oxidative environment (13). Since in the previous studies the addition of serum inhibited the LDL modification, it was suggested that in vivo, the process must occur extravascularly in microenvironments protected from naturally occurring antioxidants (13). The coculture system used in the present studies appears to provide such a microenvironment. The present observation that HDL at levels as low as $50 \mu \mathrm{g} / \mathrm{ml}$ was able to almost completely prevent the LDL-induced effects demonstrates the high protective capacity of HDL in these LDL-cell interactions. Hessler and colleagues (31) originally demonstrated that HDL protected EC in culture from the cytotoxic effects of oxidized LDL. The authors attributed the HDL effect to its protein-phospholipid components (31). van Hinsbergh and coworkers (32) subsequently demonstrated that HDL prevented the production of highly modified LDL by EC. Parthasarathy and colleagues (33) reported that inclusion of HDL in cultures of EC containing LDL had a profound inhibitory ef- fect on the subsequent degradation of the incubated and highly modified LDL by macrophages (33). The authors have suggested that similar quantities of lysophosphatidylecholine are formed in LDL/HDL coincubations. The phospholipase activity of LDL may act on HDL-associated phospholipid peroxide generating a fatty acid peroxide in the HDL particle. This, however, may not undergo rapid propagation/decomposition because of the lipid packing. HDL has been suggested to exert its protective role by: $(a)$ scavenging the prooxidant compounds; (b) by exchanging its lipids with the oxidized lipids of modified LDL; or $(c)$ by acting on the EC, protecting them from the effects of oxidized LDL. In the present studies, when PC liposomes were included in the cocultures, they effectively abolished the LDL induced increase in monocyte transmigration (Fig. 4 B). Phospholipid liposomes may also act similar to HDL in its potential ability to accept lipid peroxides from LDL. Preincubation of the cells with antioxidants before the incubation with LDL, markedly blocked the increased monocyte transmigration due to LDL modification (Fig. $5 A$ ). This may suggest that the artery wall cells in culture were capable of storing sufficient quantities of antioxidants to prevent the subsequent release of active oxygen species or to inhibit the production of oxidized cellular lipids which have been proposed as potential contributors to the initiation of lipid oxidation in LDL (13). A possible explanation for the susceptibility of LDL, but not HDL, to modification in cocultures and the resulting biologic activities here also is that phospholipase $A_{2}$ activity is associated with LDL, but not HDL. An attractive hypothesis is that the phospholipase $\mathrm{A}_{2}$ activity associated with LDL hydrolyzes the phospholipid-fatty acid peroxides formed in LDL liberating biologically active fatty acids and hydroperoxides. In the presence of HDL the phospholipid hydroperoxide (which is presumably not biologically active) partitions into the lipids of HDL and since HDL does not contain phospholipase $A_{2}$ activity the biologically active fatty acid hydroperoxides are not released (Dr. S. Parthasarathy, personal communication). Such a mechanism would be consistent with the inhibitory effect of the PC liposomes. In the present study, it is not clear why $\mathrm{HDL}_{2}$ was more effective than $\mathrm{HDL}_{3}$. Nor do the experiments presented here allow us to deduce with certainty the mechanism(s) by which HDL prevents LDL modification. However, regardless of the mechanism, in more than 22 separate experiments HDL (used in a range of $50-500 \mu \mathrm{g} / \mathrm{ml}$ ) prevented the cocultures from producing biologically active LDL (with LDL used in a range of $100-3,000 \mu \mathrm{g} / \mathrm{ml}$ ). Several studies have indicated the existence of an inverse correlation between the plasma levels of the larger $\mathrm{HDL}$ particles, the $\mathrm{HDL}_{2}$ subclass and the severity of coronary atherosclerosis in subjects with normal serum triglyceride levels (34-36). The smaller $\mathrm{HDL}_{3}$ particle, however, showed a positive association with progression of coronary atherosclerosis in the hypertriglyceridemic patients. These patients were characterized overall by decreased $\mathrm{HDL}_{2}$ and increased $\mathrm{HDL}_{3}$ concentrations (36).

The experiments in the present study used more than 400 cocultures formed from aortic wall cells from 15 different donors and lipoproteins from 13 healthy individuals. There was a significant variability in the effect of LDL preparations from various donors in these experiments in that occasionally higher concentrations of LDL $(250-500 \mu \mathrm{g} / \mathrm{ml})$ in cocultures were needed to observe a significant increase in monocyte transmigration (data not shown). It is possible that the variation in the antioxidant content of different LDL preparations or qualitative and quantitative variations in the fatty acid composition of 


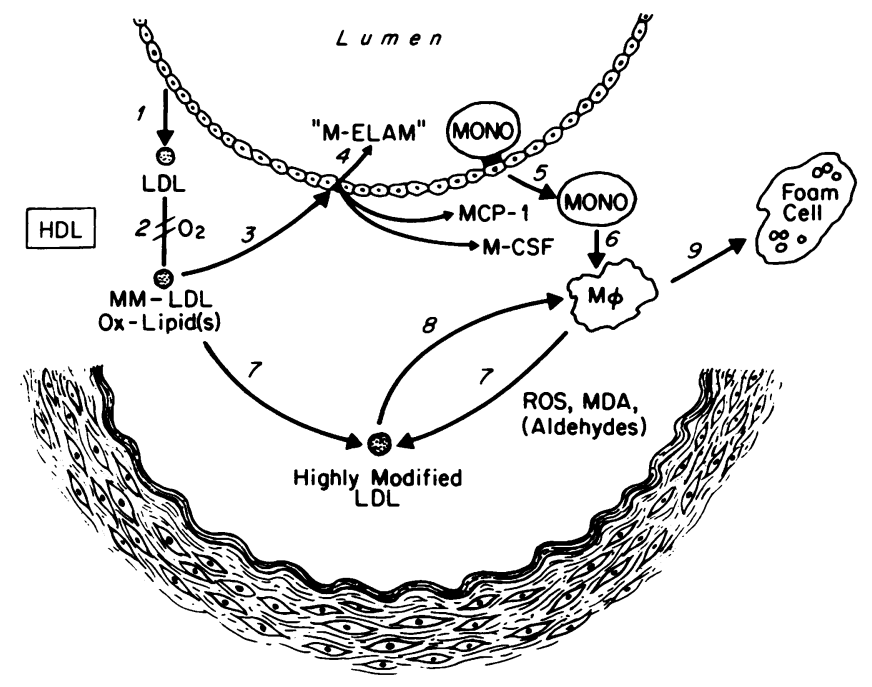

Figure 6. A proposed model for foam cell formation in the artery wall. Plasma LDL enters the largely acellular subendothelial space (I) where it is trapped in microenvironments secluded from plasma antioxidants (2). LDL lipid is oxidatively modified giving rise to a mildly oxidized LDL, MM-LDL. Once formed MM-LDL stimulates the overlaying endothelium (3) to produce an adhesion molecule (s) for blood monocytes, "M-ELAM" (4) and to secrete MCP-1 and monocyte colony-stimulating factor. These molecular events lead to the following cellular events: monocyte attachment to the EC; MCP-1 induced monocyte migration into the subendothelial space of the artery wall (5), and monocyte colony-stimulating factor induced differentiation into monocyte-macrophages (6). Macrophage products such as reactive oxygen species $(R O S)$, malondialdehyde $(M D A)$, and other aldehydes can then further modify MM-LDL to a highly modified (oxidized) form (7) which is then recognized by the macrophage scavenger receptor $(8)$ leading to cholesterol ester accumulation and foam cell formation (9). If $\mathrm{HDL}$ (presumably $\mathrm{HDL}_{2}$ ) is present in sufficient concentrations the formation of biologically active $M M$ LDL is prevented and the inflammatory reaction may be blocked.

the different LDL preparations were at least partially responsible for the observed differences as suggested by others $(37,38)$. Thus LDL obtained from rabbits fed a diet rich in oleic acid (37) or a diet containing a probucol supplement (7) has been demonstrated to be more resistant to oxidation compared to LDL from rabbits on control diets.

Based on the findings presented in this and our previous reports $(21,23,39,40)$ we propose the following scheme for the sequence of events (Fig. 6) in the development of foam cells in the artery wall: LDL becomes trapped in microenvironments in the extracellular matrix of the subendothelial space secluded from plasma antioxidants. Reactive oxygen species and/or oxidized cellular lipids may be transferred to LDL and initiate the propagation of LDL lipid peroxidation. Since at the early stages of atherogenesis the subendothelial space is largely acellular and does not contain a significant number of monocyte-macrophages releasing high levels of prooxidants, the resulting LDL is only minimally oxidized. This minimally modified LDL (MM-LDL) then can induce: the overlaying endothelium to express an adhesion molecule(s) for monocytes (23), secrete MCP-1 $(21,23)$ and macrophage-colony stimulating factor (39). These molecular events in turn induce monocyte binding, migration into the subendothelial space, and monocyte differentiation into macrophages (41). The macrophages could subsequently release reactive oxygen species (12), and aldehydes, further modifying the MM-LDL into a highly modified form which is then recognized and taken up by the macrophage scavenger and/or oxidized LDL receptor (42), resulting in foam cell formation (43). Additionally we hypothesize that if HDL (presumably $\mathrm{HDL}_{2}$ ) is present in sufficient concentrations the formation of biologically active MM-LDL is prevented and the inflammatory reaction may be blocked.

\section{Acknowledgments}

We thank Dr. Margarete Mehrabian for assistance in obtaining the cDNA for MCP-1; Drs. George Popjak, Guy Chisolm, and Sam Parthasarathy for valuable discussions; Cynthia Harper for her excellent technical assistance; and the members of the UCLA Heart Transplant Team for collecting the aortic specimens.

This work was supported in part by the U. S. Public Health Services grants HL 30568, IT 32 HL 07412, and RR 865; by the Laubisch, Rachel Israel Berro, and M. K. Grey Funds.

\section{References}

1. Morton, R. E., G. A. West, and H. R. Hoff. 1986. A low density lipoprotein sized particle isolated from human atherosclerotic lesions is internalized by macrophages via a non-scavenger mechanism. J. Lipid Res. 27:1124-1134.

2. Hoff, H. F., and J. W. Gaubatz. 1982. Isolation, purification and characterization of a lipoprotein containing Apo B from the human aorta. Arteriosclerosis. 42:273-297

3. Haberland, M. E., D. Fong, and L. Cheng. 1988. Malondialdehyde altered protein occurs in atheroma of WHHL rabbits. Science (Wash. DC). 241:215-218.

4. Palinski, W., M. E. Rosenfeld, S. Yla-Herttuala, G. C. Gurtner, S. S. Socher, S. W. Butler, S. Parthasarathy, T. E. Carew, D. Steinberg, and J. L. Witztum. 1989. LDL undergoes oxidative modification in vivo. Proc. Natl. Acad. Sci. USA. 86:1372-1380.

5. Chisolm, G. M., and D. W. Morel. 1988. Lipoprotein oxidation and cytotoxicity: effect of probucol on streptozotocin-treated rats. Am. J. Cardiol. 62:20B-26B.

6. Carew, T. E., D. C. Schwenke, and D. Steinberg. 1987. Antiatherogenic effect of probucol unrelated to the hypocholesterolmeic effect: evidence that antioxidants in vivo can selectively inhibit LDL degradation in macrophage rich fatty streaks and slow progression of atherosclerosis in the WHHL rabbit. Proc. Natl. Acad. Sci. USA. 84:7725-7729.

7. Kita, T., Y. Nagano, M. Yokode, K. Ishii, N. Kume, A. Ooshuma, H. Yoshida, and C. Kawai. 1987. Probucol prevents the progression of atherosclerosis in WHHL rabbit. Proc. Natl. Acad. Sci. USA. 84:5928-5931.

8. Bjorkhem, I., A. Henriksson-Freyschuss, O. Breuer, U. Diczfalusy, L. Berglund, and P. Henriksson. 1991. The antioxidant butylated hydroxytoluene protects against atherosclerosis. Arteriosclerosis \& Thrombosis. 11:15-22.

9. Morel, D. W., P. E. DiCorleto, and G. M. Chisolm. 1984. Endothelial and smooth muscle cells alter low density lipoprotein in vitro by free radical oxidation. Arteriosclerosis. 4:357-364.

10. Steinbrecher, U., S. Parthasarathy, D. S. Leake, J. L. Witztum, and D. Steinberg. 1984. Modification of low density lipoprotein by endothelial cells involves lipid peroxidation and degradation of low density lipoprotein phospholipids. Proc. Natl. Acad. Sci. USA. 83:3883-3887.

11. Heinecke, J. W., H. Rosen, and A. Chait. 1984. Iron and copper promote modification of LDL by human arterial smooth muscle cells. J. Clin. Invest. 74:1890-1894.

12. Cathcart, M. K., D. W. Morel, and G. M. Chisolm. 1985. Monocytes and neutrophils oxidize low density lipoprotein making it cytotoxic. J. Leukocyte Biol. 38:341-350.

13. Steinberg, D., S. Parthasarathy, T. E. Carew, J. C. Khoo, and J. L. Witztum. 1989. Beyond cholesterol. Modifications of low-density lipoprotein that increase its atherogenicity. N. Engl. J. Med. 320:915-924.

14. Navab, M., G. P. Hough, L. W. Stevenson, D. C. Drinkwater, H. Laks, and A. M. Fogelman. 1988. Monocyte migration into the subendothelial space of a coculture of adult human aortic endothelial and smooth muscle cells. J. Clin. Invest. 82:1853-1863.

15. Navab, M., F. Liao, G. P. Hough, L. A. Ross, B. J. Van Lenten, T. B Rajavashisth, A. J. Lusis, H. Laks, D. C. Drinkwater, and A. M. Fogelman. 1991. Interaction of monocytes with coculture of human aortic wall cells involves interleukins 1 and 6 with marked increases in connexin43 message. J. Clin. Invest. 87:1763-1772.

16. Fogelman, A. M., F. Elahi, K. Sykes, B. J. Van Lenten, M. C. Territo, and J. A. Berliner. 1988. Modification of the Recalde method for the isolation of human monocytes. J. Lipid Res. 29:1243-1247. 
17. Chomczynski, P., and S. Nicoletta. Single step method of RNA isolation by acid guanidinium thiocyanate-phenol-chloroform extraction. 1987. Anal. Bio chem. 162:156-159.

18. Feinberg, A. P., and B. Vogelstein. 1983. A technique for radiolabeling DNA restriction endonuclease fragments to high specific activity. Anal. Biochem. 132:6-13.

19. Havel, R. J., H. A. Eder, and J. H. Bragdon. 1955. The distribution and chemical composition of ultracentrifugally separated lipoproteins of human serum. J. Clin. Invest. 43:1345-1353.

20. Valente, A. J., D. T. Graves, C. E. Vialle-Valentin, R. Delgado, and C. J. Schwartz. 1988. Purification of a monocyte chemotactic factor secreted by nonhuman primate vascular cells in culture. Biochemistry. 27:4162-4168.

21. Cushing, S. D., J. A. Berliner, A. J. Valente, M. C. Territo, M. Navab, F. Parhamai, R. Gerrity, C. J. Schwartz, and A. M. Fogelman. 1990. Minimally modified low density lipoprotein induces monocyte chemotactic protein 1 in human endothelial cells and smooth muscle cells. Proc. Natl. Acad. Sci. USA. 87:5134-5138.

22. Lo, S. K., P. A. Detmers, S. M. Levin, and S. D. Wright. 1989. Transient adhesion of neutrophils to endothelium. J. Exp. Med. 169:1779-1793.

23. Berliner, J. A., M. C. Territo, A. Sevanian, S. Ramin, J. A. Kim, B. Bamshad, M. Esterson, and A. M. Fogelman. 1990. Minimally modified low density lipoprotein stimulates monocyte endothelial interactions. J. Clin. Invest. 85:1260-1266

24. Lowry, O. H., M. J. Rosebrough, A. L. Farr, and R. J. Randall. 1951. Protein measurement with the Folin phenol reagent. J. Biol. Chem. 193:265-275.

25. Freshney, R. I. 1987. Culture of Animal Cells. Alan R. Liss, Inc. New York. pp. 216-225, 229-232.

26. Morel, D. W., J. R. Hessler, and G. M. Chisolm. 1989. Low density lipoprotein cytotoxicity induced by free radical peroxidation of lipid. J. Lipid Res. 24:1070-1076.

27. Van Lenten, B. J., A. M. Fogelman, R. L. Jackson, S. Shapiro, M. E. Haberland, and P. A. Edwards. 1985. Receptor-mediated uptake of remnant lipoproteins by cholesterol-loaded human monocyte-macrophages. J. Biol. Chem. 260:8783-8788.

28. Elmberger, P. G., A. Kalen, U. T. Brunk, and G. Dallner. 1989. Discharge of newly synthesized dolichole and ubiquinone with lipoproteins to rat liver perfusate and to the bile. Lipids. 24:919-930.

29. Merrilees, M. J., and L. Scott. 1981. Interaction of aortic endothelial and smooth muscle cells in culture. Effect on glycosaminoglycan levels. Atherosclerosis. 39:147-161.

30. Esterbauer, H., G. Jurgens, O. Quehenberger, and E. Koller. 1987. Au- tooxidation of human low density lipoprotein: loss of polyunsaturated fatty acids and vitamin $\mathrm{E}$ and generation of aldehydes. J. Lipid Res. 28:495-509.

31. Hessler, J. R., A. L. Robertson, Jr., and G. M. Chisolm. 1979. LDL-induced cytotoxicity and its inhibition by HDL in human vascular smooth muscle and endothelial cells in culture. Arteriosclerosis. 32:213-229.

32. van Hinsbergh, V. W., M. Scheffer, L. Havekes, and H. J. Kemper. 1986. Role of endothelial cells and their products in the modification of low density lipoproteins. Biochim. Biophys. Acta. 878:49-64.

33. Parthasarathy, S, J. Barnett, and L. G. Fong. 1990. High-density lipoprotein inhibits the oxidative modification of low-density lipoprotein. Biochim. Biophys. Acta. 1044:275-283.

34. Ballantyne, F. R. S. Clark, H. S. Simpson, and D. Ballantyne. 1982. High density and low density lipoproteins in survivors of myocardial infarction and in control subjects. Metabolism (Clin. \& Exp.) 31:433-437.

35. Tall, A. R. 1990. Plasma high density lipoproteins. Metabolism and relationship to atherogenesis. J. Clin. Invest. 86:379-84.

36. Johansson, J., L. A. Carlson, C. Landou, and A. Hamsten. 1991. High density lipoproteins and coronary atherosclerosis. A strong inverse relation with the largest particles is confined to normotriglyceridemic patients. Arteriosclerosis \& Thrombosis. 11:174-182.

37. Parthasarathy, S., J. C. Khoo, E. Miller, J. Barnett, J. L. Witztum, and D. Steinberg. 1990. Low density lipoprotein rich in oleic acid is protected against oxidative modification: implications for dietary prevention of atherosclerosis. Proc. Natl. Acad. Sci. USA. 87:3894-3898.

38. Lenz, M. L., H. Hughes, J. R. Mitchell, D. P. Via, J. R. Guyton, A. A. Taylor, A. M. Gotto, Jr., and C. V. Smith. 1990. Lipid hydroperoxy and hydroxy derivatives in copper-catalyzed oxidation of low density lipoprotein. J. Lipid Res. 31:1043-1050.

39. Rajavashisth, T. B., A. Andalibi, M. C. Territo, J. A. Berliner, M. Navab, A. M. Fogelman, and A. J. Lusis. 1990. Modified low density lipoproteins induce endothelial cell expression of granulocyte and macrophage colony stimulating factors. Nature (Lond.). 344:254-257.

40. Liao, F., J. A. Berliner, M. Mehrabian, M. Navab, L. L. Demer, A. J. Lusis, and A. M. Fogelman. 1991. Minimally modified low density lipoprotein is biologically active in vivo in mice. J. Clin. Invest. 87:2253-2257.

41. Metcalf, D. 1989. The molecular control of cell division, differentiation commitment and maturation in haemopoietic cells. Nature (Lond.). 339:27-30.

42. Sparrow, C. P., S. Parthasarathy, and D. Steinberg. 1989. A macrophage receptor that recognizes oxidized low density lipoprotein but not acetylated low density lipoprotein. J. Biol. Chem. 264:2599-2604.

43. Brown, M. S., and J. L. Goldstein. 1990. Scavenging for receptors. Nature (Lond.). 343:508-509. 